\title{
PENGEMBANGAN SISTEM EKSTRAKSI METADATA ARTIKEL ILMIAH SECARA OTOMATIS
}

\author{
Faisal Rahutomo', Dyah Ayu Irawati ${ }^{2}$, Muhammad Aisamuddin Eka Pramudita ${ }^{3}$ \\ 1,2,3 Jurusan Teknologi Informasi, Politeknik Negeri Malang \\ Email: ${ }^{1}$ faisal@polinema.ac.id, ${ }^{2}$ dyah.ayu@ @olinema.ac.id, ${ }^{3}$ muhaisamuddinep@ gmail.com
}

(Naskah masuk: 11 November 2018, diterima untuk diterbitkan: 18 Desember 2018)

\begin{abstract}
Abstrak
Pengarsipan artikel ilmiah di Jurusan Teknologi Informasi Politeknik Negeri Malang menggunakan platform Open Journal Systems (OJS). Pengarsipan tersebut melalui tahapan penulisan metadata artikel ilmiah yang dilakukan satu-persatu. Metadata artikel ilmiah ini berupa judul, penulis, instansi, surel penulis, abstrak, kata kunci, dan daftar pustaka. Diperlukan waktu yang cukup lama untuk memasukkan metadata artikel ilmiah dalam OJS karena prosedur dalam OJS itu sendiri. Untuk itu penelitian ini mengusulkan sebuah sistem tambahan OJS yang bisa menyediakan metadata artikel ilmiah tersebut secara otomatis. Sistem dibangun menggunakan pendekatan rule-based text parsing. Dalam metode tersebut disusun beberapa aturan untuk mengambil teks yang diperlukan oleh isian metadata OJS yang mewakili sebuah artikel ilmiah. Artikel ilmiah diunggah ke dalam sistem tambahan tersebut untuk menghasilkan metadata-nya secara otomatis. Metadata tersebut selanjutnya disimpan dalam format $X M L$. Pada sistem OJS terdapat perangkat native XML plugin yang bisa melakukan export - import metadata suatu artikel ilmiah untuk OJS. Dari hasil pengujian, sistem bisa memudahkan pengarsipan artikel ilmiah lebih cepat 13 kali dibanding pengisian metadata secara manual.
\end{abstract}

Kata kunci: artikel ilmiah, metadata, rule-based text parsing, open journal systems

\section{DEVELOPMENT OF AUTOMATIC SCIENTIFIC ARTICLE METADATA EXTRACTION SYSTEM}

\begin{abstract}
Department of information technology, State Polytechnic of Malang archives its scientific article with Open Journal Systems (OJS) platform. Archiving in OJS needs to write the scientific article metadata manually through a form. Metadata of this scientific article includes title, author, agency, writer e-mail, abstract, keywords and bibliography. Inserting scientific articles metadata in OJS manually takes quite a long time because of the procedure in OJS itself. Highlighting this problem, this research proposes a text processing addon system for OJS that able to extract the scientific article's metadata automatically. The system is built with rule-based text parsing method. In this method, the authors composed some rules to obtain the metadata of scientific article. Scientific articles were uploaded into the system to capture the metadata of the scientific article automatically. The metadata was then stored in XML. In OJS add-on there is native XML plugin tool that able to export - import the scientific article metadata for OJS. The experimental results show the system able to facilitate the archiving of scientific articles 13 times faster.
\end{abstract}

Keywords: scientific articles, metadata, rule-based text parsing, open journal systems

\section{PENDAHULUAN}

Bertambahnya artikel ilmiah setiap tahunnya adalah sebuah kepastian. Hal ini disebabkan setiap universitas wajib menghasilkan artikel ilmiah, baik bagi mahasiswa untuk syarat kelulusan, dan juga bagi dosen sebagai salah satu luaran penelitiannya. Sehingga, semakin tahun jumlah artikel ilmiah terus bertambah semakin banyak. Artikel ilmiah dalam setiap terbitan bisa dan seringkali memiliki aturan format yang berbeda-beda. Meskipun formatnya tampilannya berbeda tetapi dalam tata aturan penulisan artikel ilmiahnya memiliki kemiripan.

Dewasa ini, pengarsipan artikel ilmiah dapat menggunakan kerangka sistem Open Journal Systems (OJS) (Project, 2016). Petugas yang mengunggah artikel tersebut harus mengetikkan atau memasukkan informasi metadata artikel yang diunggah. Sayangnya pembuatan metadata masih dilakukan secara manual. Berdasarkan uraian di atas, maka perlu dibangun sebuah sistem yang dapat memudahkan petugas dalam mengunggah artikel 
ilmiah. Petugas hanya perlu mengunggah berkas artikel ilmiah tersebut tanpa perlu memasukkan informasi metadata yang ada pada file tersebut secara manual. Hal ini dimungkinkan karena metadata artikel sudah diekstraksi secara otomatis oleh sistem di dalam penelitian ini.

Pendekatan yang dipilih adalah pendekatan praktis, dengan metode rule-based text parsing (Russell \& Norvig, 2009)(Yates \& Neto, 2008)(Manning, Raghavan and Schütze, 2008). Pola teks yang ada di dalam makalah ilmiah dipetakan ciri-cirinya untuk dibuat aturan ekstraksinya. Informasi penting yang telah diekstraksi kemudian disimpan ke dalam format $X M L$, menyesuaikan addon OJS yang telah tersedia. Dengan demikian makalah diharapkan dapat diarsipkan secara lebih cepat tanpa kerepotan berlebih memasukkan metadata artikel satu-persatu.

Makalah ini disusun ke dalam lima bagian. Bagian pertama membahas pendahuluan. Bagian kedua membahas studi literatur yang mendasari penelitian ini. Bagian ketiga membahas metode yang diusulkan pada makalah ini. Bagian keempat membahas pengujian dan pembahasan. Diakhiri oleh bagian kelima yang memaparkan simpulan dari penelitian ini.

\section{TINJAUAN PUSTAKA}

\subsection{Metadata}

Metadata adalah data tentang data. Sebuah file, yang merupakan sebuah data memiliki data lain yang menginformasikan tentang file tersebut. Metadata adalah informasi terstruktur yang mendeskripsikan, menjelaskan, menemukan, atau setidaknya membuat menjadikan suatu informasi mudah untuk ditemukan kembali, digunakan, atau dikelola. Metadata sering disebut sebagai data tentang data atau informasi tentang informasi. Metadata ini mengandung informasi mengenai isi dari suatu data yang dipakai untuk keperluan manajemen file atau data itu nantinya dalam suatu basis data (NISO, 2004).

Metadata untuk artikel adalah informasi mengenai artikel. Misalnya data pengarang, judul artikel, tahun, tanggal publikasi. Dapat pula merupakan bahan deskriptif seperti kata kunci dan abstrak. Sehingga, untuk memudahkan pengarsipan dan pencarian kembali sebuah artikel ilmiah dibutuhkan sebuah metadata dari artikel ilmiah itu sendiri.

\subsection{Text Parsing}

Text parsing adalah teknik komputer membaca teks dan memaknainya. Sebuah dokumen dikenali sebagai kumpulan kata-kata atau teks biasa tanpa format tertentu. Kemudian teks di dalam dokumen tersebut dipecah menjadi bagian-bagian kecil yang bisa dimengerti. Dalam kasus kompiler pemahaman komputer terhadap bagian-bagian kecil teks tersebut dimanfaatkan lebih lanjut ke dalam tahap kompilasi. Sedangkan pada kasus ekstraksi informasi, pemahaman bagian-bagian kecil teks tersebut dipahami sebagai informasi yang berhasil diekstrak dari sebuah dokumen. Agar komputer dapat memahaminya bagian kecil teks yang dimaksud, diperlukan ciri-ciri dan tanda-tanda khusus atau aturan sintaks tertentu di dalam dokumen (Manning \& Schütze, 1999).

\subsection{Rule-Based Expert System}

Rule-based adalah salah satu pendekatan atau algoritma dalam ilmu teknologi informasi yang bisa digunakan untuk berbagai permasalahan. Rule-based sesuai untuk semua bidang yang mana area masalahnya dapat ditulis dalam bentuk pernyataan aturan if-then. Rangkaian aturan if-then ini bisa disusun berantai hingga menghubungkan antara anteseden dan konsekuensi. Relasi logika atau, tidak, atau dan dapat dikombinasikan di dalam aturan ifthen yang dibangun (Russell \& Norvig, 2009).

\section{$2.4 O J S$}

OJS adalah sistem yang digunakan untuk mengelola artikel ilmiah. Ia dirancang untuk memfasilitasi pengembangan akses terbuka publikasi ilmiah dengan peer-review. OJS menyediakan infrastruktur teknis tidak hanya untuk presentasi artikel jurnal secara daring, namun juga keseluruhan alur kerja manajemen editorial. Termasuk di dalamnya kiriman artikel, beberapa putaran peer-review, dan pengindeksan. Dalam situs resminya (Project, 2016) disebutkan, OJS adalah perangkat lunak terbuka yang tersedia secara bebas untuk jurnal di seluruh dunia. OJS membuat sistem akses terbuka agar ada lebih banyak jurnal terbuka. Karena, akses yang terbuka dapat meningkatkan pembaca jurnal serta kontribusinya terhadap kebaikan publik dalam skala global.

\section{EKSTRAKSI METADATA}

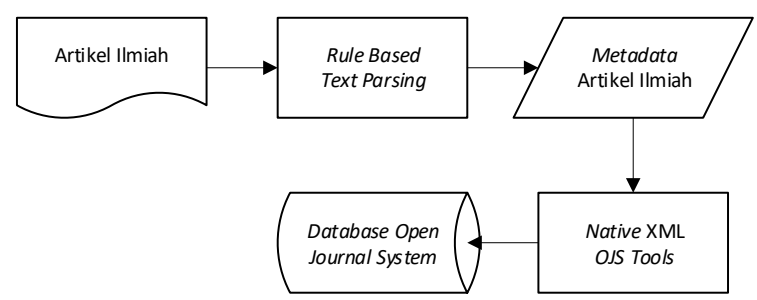

Gambar 1. Diagram alir sistem

Pada penelitian ini metadata yang diekstrak adalah metadata dari suatu artikel ilmiah. Gambar 1 mendeskripsikan langkah-langkah yang dilakukan di dalam usulan penelitian ini. Pertama, artikel ilmiah diubah menjadi teks biasa tanpa format. Selanjutnya penyusunan serangkaian aturan if-then atas ciri-ciri yang dapat dikenal di dalam makalah ilmiah atas 
informasi-informasi apa saja yang ingin diekstrak dari dokumen. Selanjutnya kumpulan aturan ini diimplementasikan dalam bentuk regular expression. Luaran dari aturan-aturan ini adalah sekumpulan informasi yang kemudian disusun dan disesuaikan ke dalam bentuk standar native XML plugin. Untuk itu percobaan export XML dilakukan terlebih dahulu atas sebuah makalah yang telah diunggah manual untuk mengenali struktur $X M L$ yang dimaksud. Setelah itu sistem diintegrasikan untuk menjadi sebuah perangkat yang berguna.

\subsection{Pengumpulan Data}

Pada tahap ini pengumpulkan data dan informasi yang diperlukan dilakukan untuk melakukan ekstraksi metadata artikel ilmiah. Artikel ilmiah yang dimaksud di dalam makalah ini berasal dari laman jurnal Politeknik Negeri Malang (Polinema), lebih spesifik di dalam Jurnal Informatika Polinema (JIP) (Malang, 2018). Artikel ilmiah yang digunakan adalah publikasi dari tahun 2014 hingga 2017. Penelitian ini masih membatasi karena satu format artikel ilmiah. Dengan demikian aturan-aturan di dalam algoritma rule-based text parsing dibatasi pada satu format artikel ilmiah JIP. Algoritma rule-based yang dinamik dapat dikembangkan lebih lanjut sebagai pengembangan makalah ini. Sistem yang dibangun dibatasi hanya menerima masukkan berupa berkas berformat pdf.

\subsection{Pengembangan Sistem}

Pada sistem ini proses pengembangan dilakukan dengan menggunakan bahasa pemrograman PHP. Untuk melakukan pembacaan berkas pdf digunakan komponen PdfParser yang dikembangkan oleh Malot (Malot, 2018). Bagian lainnya dari program dibangun dengan PHP. Pengembangan aplikasi ini diikuti dengan pengujian yang bertujuan untuk mengecek fungsi setiap fitur yang terdapat pada sistem agar setiap fitur yang ada bekerja sesuai perancangan. Proses pengujian pada sistem yang dikembangkan menggunakan web browser dan dilakukan dengan menguji fungsionalitas dari setiap fitur yang tersedia pada sistem. Pengujian ini dilakukan setiap saat setelah satu fitur selesai dibuat. Proses ini dilakukan hingga setiap fitur bekerja sesuai dengan yang direncanakan.

Antarmuka dari halaman awal ditunjukkan oleh Gambar 2. Bagian atas halaman awal ini berisi form upload berkas. Bagian tengahnya berisi tabel yang berisi daftar artikel ilmiah yang sebelumnya sudah pernah diunggah. Kemudian terdapat beberapa tombol untuk menghapus, melihat detail dan mengunduh file XML yang berisi metadata dari artikel ilmiah. Antarmuka dari detail metadata menampilkan detail metadata dari artikel ilmiah yang sudah diunggah berupa popup seperti yang ditunjukkan pada Gambar 3. Pengguna dapat mengevaluasinya sebelum digunakan lebih lanjut.
Apabila tombol extract ditekan, berkas $X M L$ dapat diunduh untuk digunakan lebih lanjut.
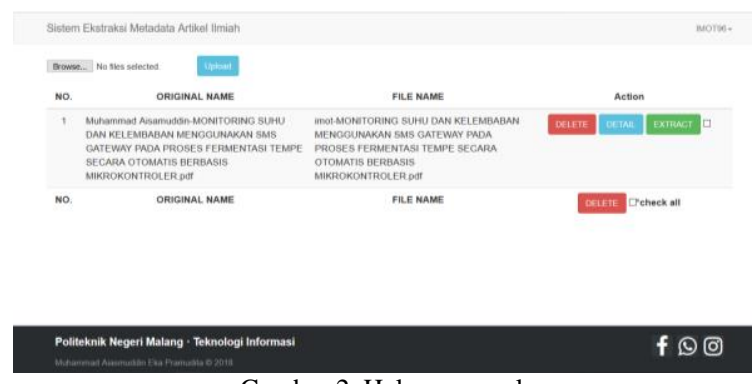

Gambar 2. Halaman awal

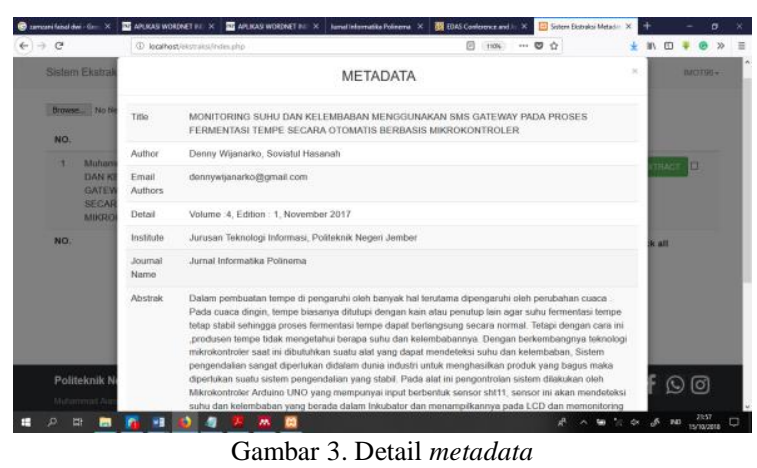

\subsection{Implementasi Rule Based Text Parsing}

Penelitian ini merancang alur kerja sistem berdasarkan penelitian Zamzami dkk (Zamzami, $\mathrm{dkk}, 2016$ ), yang juga menggunakan algoritme rulebased text parsing. Pada penelitian tersebut dilakukan percobaan penyusunan WordNet Bahasa Indonesia yang diambil dari sumber Kamus Tesaurus Bahasa Indonesia (Bahasa, 2008).

\begin{tabular}{ll}
\multicolumn{2}{c}{ Tabel 1. Tabel Ciri-Ciri yang Dikenali } \\
\hline ciri-ciri & informasi \\
\hline $\begin{array}{l}\text { Sebelum bertemu kata / kalimat dengan huruf } \\
\text { besar semua atau diawali dengan kata }\end{array}$ & $\begin{array}{l}\text { Header } \\
\text { (Volume, }\end{array}$ \\
$\begin{array}{l}\text { Volume dan diakhiri dengan angka sebelum } \\
\text { bertemu dengan kata. }\end{array}$ & $\begin{array}{l}\text { Edisi dan } \\
\text { Tahun) }\end{array}$ \\
Kata / kalimat dengan huruf besar semua. & Judul \\
Setelah kata / kalimat dengan huruf besar & Nama \\
semua, sebelum bertemu angka. & \\
$\begin{array}{l}\text { Setelah angka yang dibatasi koma. } \\
\text { Kata yang terdapat karakter @, dibatasi } \\
\text { dengan koma (,). }\end{array}$ & Instansi \\
$\begin{array}{l}\text { Setelah kata Abstrak sebelum bertemu kata } \\
\text { kunci. }\end{array}$ & Abstrak \\
$\begin{array}{l}\text { Setelah kata kunci, dibatasi koma, sebelum } \\
\text { pendahuluan. }\end{array}$ & Kata kunci \\
$\begin{array}{l}\text { Dimulai setelah kata (daftar pustaka:). } \\
\text { Kemudian referensi tersebut dikategorikan } \\
\text { lagi menurut nama penulis, tahun terbit, } \\
\text { judul, dan sumber yang dipisahkan dengan } \\
\text { karakter titik (.). }\end{array}$ & Referensi \\
\hline
\end{tabular}

Setelah data yang berupa artikel tersebut didapatkan, maka langkah selanjutnya adalah mengidentifikasi ciri-ciri penting yang dapat dikenali dari dokumen untuk mengambil informasiinformasi tertentunya saja. Tabel 1 menjelaskan ciriciri yang dikenali di dalam dokumen, terkait dengan 
informasi-informasi yang diinginkan untuk diambil di dalam metode ini.

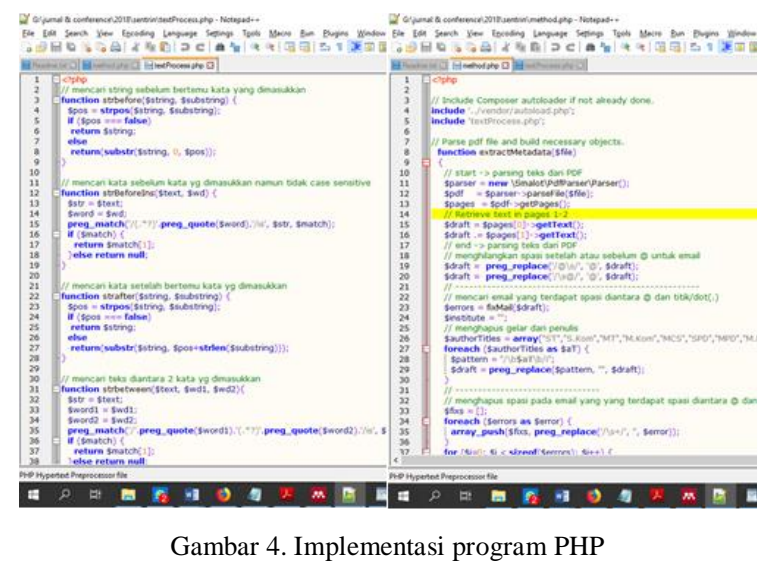

Gambar 4 menunjukkan screenshoot sebagian implementasi rule-based di dalam kode PHP. Kode di dalam penelitian ini akan dibuat akses terbuka melalui lama Github setelah artikel ini terbit.

\section{PENGUJIAN DAN PEMBAHASAN}

Dalam tahap ini dilakukan uji coba aplikasi yang dibuat. Pengujian aplikasi yang dilakukan meliputi ekstraksi aplikasi apakah sudah sesuai dengan yang diharapkan. Hasil pengujian menunjukkan pada akhirnya semua fitur aplikasi dapat berfungsi sebagaimana yang direncanakan.

Setelah setiap fitur berfungsi dengan benar, tahap selanjutnya adalah tahap pengujian performa sistem. Tujuannya untuk evaluasi apakah usulan di dalam penelitian ini memiliki performa yang lebih baik dibandingkan tanpanya. Pada tahap ini, akan dilakukan beberapa metode pengujian, yaitu pengukuran akurasi dan waktu sistem dalam melakukan ekstraksi. Pengukuran akurasi dilakukan untuk mengukur tingkat kesesuaian ekstraksi metadata oleh sistem dengan ekstraksi metadata yang dilakukan secara manual. Pengujian waktu dilakukan untuk mengukur tingkat kecepatan ekstraksi metadata artikel ilmiah oleh sistem dibandingkan dengan ekstraksi yang dilakukan secara manual untuk dimasukkan ke dalam OJS.

\subsection{Akurasi Sistem}

Pengujian ini dilakukan dengan mengambil file uji coba sebanyak $10 \%$ dari setiap Volume Jurnal Informatika Polinema. Pengujian ini dilakukan pada artikel yang telah terbit, yang telah ditulis dengan format tata tulis yang sesuai dengan template yang disediakan. Tabel 2 mencatat hasil percobaan yang dilakukan. Dari data tersebut maka dapat dihitung tingkat akurasi sistem terlihat pada perhitungan dengan rumus seperti di bawah ini:

$$
\text { Akurasi }=\frac{7 \times 15-5}{7 \times 15} \times 100 \%=95 \%
$$

Dengan demikian dapat diketahui bahwa sistem dapat bekerja dengan baik apabila dari file pdf dari artikel ilmiah bisa di-parsing dengan baik. Selain itu format aturan penulisan dalam jurnal juga sangat berpengaruh dalam kinerja sistem ini, karena menggunakan metode rule-based text-parsing yang statik, belum dinamik.

\begin{tabular}{|c|c|c|c|c|c|c|c|}
\hline NO & 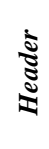 & $\stackrel{\Xi}{\Xi}$ & $\begin{array}{l}\stackrel{\Xi}{\Xi} \\
\text { Z }\end{array}$ & 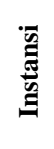 & 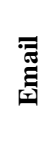 & 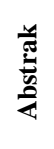 & 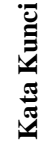 \\
\hline 1 & $\checkmark$ & $\checkmark$ & $\checkmark$ & $\checkmark$ & $\checkmark$ & $\checkmark$ & $\checkmark$ \\
\hline 2 & $\checkmark$ & $\checkmark$ & $\checkmark$ & $\checkmark$ & $\checkmark$ & $\checkmark$ & $\checkmark$ \\
\hline 3 & $\checkmark$ & $\checkmark$ & $\checkmark$ & $\checkmark$ & $\checkmark$ & $\checkmark$ & $\checkmark$ \\
\hline 4 & $\checkmark$ & $\checkmark$ & $\checkmark$ & $\checkmark$ & $\checkmark$ & $\checkmark$ & $\checkmark$ \\
\hline 5 & $\checkmark$ & $\checkmark$ & $\checkmark$ & $\checkmark$ & $\checkmark$ & $\checkmark$ & $\checkmark$ \\
\hline 6 & $\checkmark$ & $\checkmark$ & $\checkmark$ & $\checkmark$ & - & $\checkmark$ & $\checkmark$ \\
\hline 7 & $\checkmark$ & $\checkmark$ & $\checkmark$ & $\checkmark$ & $\bar{\checkmark}$ & $\checkmark$ & $\checkmark$ \\
\hline 8 & $\checkmark$ & $\checkmark$ & $\checkmark$ & $\checkmark$ & $\checkmark$ & $\checkmark$ & $\checkmark$ \\
\hline 9 & $\checkmark$ & $\checkmark$ & $\checkmark$ & $\checkmark$ & $\checkmark$ & $\checkmark$ & $\checkmark$ \\
\hline 10 & $\checkmark$ & $\checkmark$ & $\checkmark$ & $\checkmark$ & $\checkmark$ & $\checkmark$ & $\checkmark$ \\
\hline 11 & $\checkmark$ & $\checkmark$ & $\checkmark$ & $\checkmark$ & $\checkmark$ & $\checkmark$ & $\checkmark$ \\
\hline 12 & $\checkmark$ & $\checkmark$ & $\checkmark$ & $\checkmark$ & $\checkmark$ & $\checkmark$ & $\checkmark$ \\
\hline 13 & $\checkmark$ & $\checkmark$ & $\checkmark$ & $\checkmark$ & $\checkmark$ & $\checkmark$ & $\checkmark$ \\
\hline 14 & $\checkmark$ & - & - & $\checkmark$ & $\checkmark$ & $\checkmark$ & $\checkmark$ \\
\hline 15 & $\checkmark$ & - & - & $\checkmark$ & $\checkmark$ & $\checkmark$ & $\checkmark$ \\
\hline
\end{tabular}

\subsection{Waktu Kinerja Sistem}

Pengujian ini dilakukan dengan meminta 3 orang pengguna untuk memasukkan 10 data artikel ilmiah pada OJS secara manual dan dengan sistem yang dibuat. Kemudian dibandingkan lebih cepat mana memasukkan data artikel ilmiah dengan sistem atau secara manual. Tabel 3 menunjukkan hasil dari pengujian tersebut.

\begin{tabular}{ccc}
\multicolumn{3}{c}{ Tabel 3. Pengujian Waktu } \\
\hline \multirow{2}{*}{ No. } & \multicolumn{2}{c}{ Waktu } \\
\cline { 2 - 3 } & Manual & Sistem \\
\hline 1 & 1 menit 1 detik & 14 menit 53 detik \\
2 & 1 menit 35 detik & 20 menit 29 detik \\
3 & 1 menit 20 detik & 16 menit 41 detik \\
Rata-rata & 78,67 detik & 1041 detik \\
\hline
\end{tabular}

Dari data tersebut dapat diproses untuk mengukur efisiensi waktu dalam mengunggah artikel ilmiah menggunakan sistem dibandingkan dengan secara manual pada OJS. Perhitungan efisiensi waktu dilakukan seperti pada rumus di bawah ini:

$$
\text { Perbandingan Waktu }=\frac{\text { Manual }(\text { detik })}{\text { Sistem }(\text { detik })}
$$

Dengan rumus tersebut dapat dihitung perbandingan waktu menggunakan sistem adalah 13,23 kali lebih cepat dibanding memasukkan data secara manual. 


\section{KESIMPULAN}

Berdasarkan hasil pengujian dapat disimpulkan bahwa Sistem Ekstraksi Metadata Artikel Ilmiah dapat dibangun dengan menggunakan metode rulebased text parsing. Sistem yang dibangun berhasil mengekstraki metadata dari artikel ilmiah JIP dengan baik, memiliki nilai galat kurang dari $10 \%$. Galat yang ada dimungkinkan karena kesalahan pembacaan karakter berkas pdf ke teks oleh komponen PdfParser. Kemungkinan lainnya dikarenakan kesalahan penulisan artikel, tidak sesuai template. Selain itu sistem ekstraksi metadata artikel ilmiah ini lebih efisien dalam memasukkan data artikel ilmiah pada OJS. Pengujian mencatat pendekatan dengan sistem 13,23 kali lebih cepat dibanding masukan secara manual.

Saran yang dapat diberikan dari hasil penelitian untuk pengembangan sistem ini ke depan yaitu ekstraksi dengan metode yang lebih cerdas dan dinamik, yang dapat mengenali format artikel ilmiah dengan template yang berbeda-beda.

\section{DAFTAR PUSTAKA}

BAEZA-YATES, R. AND RIBEIRO-NETO, B., 2008. Modern Information Retrieval: The Concepts and Technology Behind Search. 2nd edn. USA: Addison-Wesley Publishing Company.

BAHASA, P., 2008. Kamus Tesaurus Bahasa Indonesia. Departemen Pendidikan Nasional.

MALANG, J. T. I. P. N., 2018. Jurnal Informatika Polinema (JIP). Available at: http://jip.polinema.ac.id/ojs3/index.php/jip.

MALOT, S., 2018. PDF Parser. Available at: https://pdfparser.org/.

MANNING, C. D., RAGHAVAN, P. AND SCHÜTZE, H., 2008. Introduction to Information Retrieval. New York, NY, USA: Cambridge University Press.

MANNING, C. D. AND SCHÜTZE, H., 1999. Foundations of Statistical Natural Language Processing. Cambridge, MA, USA: MIT Press.

NISO, 2004. Understanding metadata. 4733 Bethesda Avenue, Suite 300, Bethesda, MD 20814 USA: NISO. Available at: http://www.niso.org/publications/press/Und erstandingMetadata.pdf.

PROJECT, P. K., 2016. Open Journal Systems. Available at: https://pkp.sfu.ca/ojs/.

RUSSELL, S. AND NORVIG, P., 2009. Artificial Intelligence: A Modern Approach. 3rd edn. Upper Saddle River, NJ, USA: Prentice Hall Press.

ZAMZAMI, D., RAHUTOMO, F. AND PUSPITASARI, D., 2016. 'Aplikasi
Wordnet Indonesia Berdasarkan Kamus Thesaurus Bahasa Indonesia menggunakan Algoritma Rule Based Text Parsing', in Seminar Informatika Aplikatif Polinema. Jurusan Teknologi Informasi Politeknik Negeri Malang. 
Halaman ini sengaja dikosongkan 